\title{
Achievements in an Event Semantics
}

\author{
Christopher Piñón \\ Universität Düsseldorf
}

\section{Introduction}

The category of achievements forms one of the four cornerstones of Vendler's (1967) aspectual classification, among accomplishments, activities, and states. Examples of achievement verbs are given in (1).

arrive, be born, begin, convince, depart, die, discover, find, forget, hear, leave, lose, notice, realize, recognize, resume, see, stop, strike oil, win

A long-standing intuition about achievements is that they denote instantaneous events. In Vendler's words, achievements 'occur at a single moment' (p. 103) and 'involve unique and definite time instants' (p. 107). Similarly, Freed (1979, p. 51) states that ' $[\mathrm{a}] \mathrm{n}$ achievement essentially names an event that has no duration.' Putting the same point in yet another way, Mourelatos (1981, p. 192) writes that achievements 'can be indefinitely placed within a temporal stretch, but they cannot in themselves occur over or throughout a temporal stretch.' The instantaneity that these authors speak of is palpable in the following sentences:

(2) a. Rebecca reached the summit at twelve o'clock sharp.

b. Anita recognized Peter the moment he entered the room.

In (2a), Rebecca's reaching (attainment) of the summit occurred exactly at twelve o'clock - it did not last several moments, the final of which was the transition to 12:00. Similarly, in (2b), Anita's recognition of Peter took place the moment he entered-no sooner, no later, and certainly no longer.

But do achievements really denote instantaneous events? A positive answer requires there to be instantaneous events, and yet this is open to doubt. If achievements denote events and events are changes, then assuming that changes require longer than an instant to transpire, 1 it follows that there are no strictly instantaneous events. Consequently, achievements denote at best very short events, and the characterizations offered by Vendler, Freed, and Mourelatos should be charitably understood as impressionistic.

However, this conclusion may be too hasty. Let us grant that changes take time, however short. What can then be questioned is whether all events are changes. States, presumably, are not changes, but this is not what I have in mind. Imagine that there are instantaneous events which-while not changes themselves-nonetheless presuppose changes in their immediate vicinity. The presupposition in question is above all ontological: because of what they are, instantaneous events are such as to require the existence of other types of events in order to exist themselves. I will argue that there are such instantaneous events and that they can serve as the denotata of achievements.

While (finite) events come in different sizes, they all have beginnings and endings. We could take beginnings and endings to be extended events in their own right, as the earlier and later parts of a larger event, respectively. However, it cannot

(C) 1997 by Christopher Piñón Aaron Lawson (ed), SALT VII, 276-293, Ithaca, NY: Cornell University. 
be denied that an event also begins to take place at some instant and finishes taking place at another (Chisholm (1982)). Now recall the scenario from (1a): Rebecca climbs all morning and reaches the summit at twelve o'clock sharp. Never mind that we are not actually able to calculate the exact instant at which she reaches the summit. Forget also that there is a good deal of arbitrariness in determining the precise bounds of the summit. The point is simply that once we stipulate the bounds of the summit and decide on an interval (however short) which covers the ending of the climbing, we have no conceptual difficulty in imagining that the Rebecca's climbing to the summit terminates with her reaching of the summit and that the reaching is instantaneous, falling within the said interval. In other words, there is no conceptual problem in taking the reaching of the summit-as the ending of the climb to the summit-to be arbitrarily short.

The logic of achievements is in fact the logic of beginnings and endings. And it seems that beginnings and endings must satisfy two basic requirements if they are to count as beginnings and endings at all. The first is that the beginning (ending) of an event of type $X$ not be immediately preceded (followed) by an event of the same type. For example, if Rebecca begins to climb, then she was not climbing immediately before. The second requirement is that the beginning (ending) of an event of type $X$ be part of an event of the same type that stretches temporally to the right (left). Keeping with our example, if Rebecca begins to climb, then she climbs for a while immediately thereafter - not necessarily for a long while, of course, but for at least a good deal longer than an instant.

Consider now how achievement verbs like reach and recognize are amenable to this sort of analysis. Take recognize: it plausibly denotes beginnings of states of recognizing. 2 Accordingly, if Anita suddenly recognizes Peter, then there is a beginning of a state in which she recognizes him. As required, this state stretches temporally to the right and its beginning is not immediately preceded by a state in which she recognizes him. The verb reach, I suggest, denotes endings of motion events that are also beginnings of states. If Rebecca reaches the summit, then there is a ending of a motion event in which she climbs to the summit. However, that ending is at the same time the beginning of a state in which she is at the summit. As necessary, Rebecca's climbing to the summit stretches temporally to the left and its ending is not immediately followed by an event in which she climbs to the summit. Moreover, her being at the summit stretches temporally to the right and its beginning is not immediately preceded by a state in which she is at the summit.

The formalization of this analysis of achievements is problematic in current versions of event semantics (e.g., Krifka (1989), Parsons (1990)). The central difficulty, no surprise, lies in the introduction of instantaneous events-events that are located in time but which do not take up any time at all. Event semantics does not standardly assume the existence of such events. The analysis that I develop in section 3, in which I present a two-sorted event ontology for event semantics, radically changes all of this. The two sorts are introduced there as happenings and boundary happenings. Happenings correspond more or less to the familiar collection of (thick) eventualities; 3 boundary happenings are the new (thin) citizens-in a word, they are the boundaries of happenings. Concomitant with this explicit reification of boundaries is a shift from a purely mereological framework to a mereotopological one in which happenings and boundary happenings may and in fact do play according to different rules. 


\section{Diagnosing Achievements}

At the outset, let me fix some terminology. I use the term 'achievement' to designate a class of verbal projections (Vs, VPs, and IPs) that pattern alike with respect to an inventory of aspectual tests. ${ }^{4}$ This usage does not commit me to a particular denotation for achievements. However, since I presuppose an event semantics, I do assume that achievements denote properties of eventualities. 5 Whether these properties form an aspectually significant natural class or sort is of course what is at issue. In what follows, I present four pieces of evidence in favor of treating achievements as an aspectual category in their own right. In each case, I argue that the key to understanding the pattern is the instantaneity of the eventualities denoted by achievements.

\subsection{Time-Span Adverbials}

Although achievements are compatible with time-span adverbials (i.e., in-adverbials), the latter do not measure the smallest interval during which the described eventuality takes place, but rather a contextually determined interval at the end of which it takes place.

(3) a. Rebecca reached the summit in five hours (in a split second).

b. Anita recognized Peter in five minutes (in a fraction of a second).

c. Mary arrived in an hour (in a moment).

Evidence for this role of time-span adverbials with achievements is their close synonymy with after-adverbials, as the close synonymy between the sentences in ( 3 ) and (4) attests.

(4) a. Rebecca reached the summit after five hours (after a split second).

b. Anita recognized Peter after five minutes (after a fraction of a second).

c. Mary arrived after an hour (after a moment).

The close synonymy between time-span adverbials and after-adverbials is absent with accomplishments, as seen in (5). 6

(5) a. Rebecca wrote a letter to the president in an hour. Not synonymous with: Rebecca wrote a letter to the president after an hour.

b. Anita proved the theorem in twenty minutes. Not synonymous with: Anita proved the theorem after twenty minutes.

If achievements denote instantaneous eventualities, then these eventualities literally have no temporal extent to be measured. Time-span adverbials, when they measure the smallest interval during which the described eventuality takes place, presuppose a temporal extent, however short. It is this conflict between the actual lack of a temporal extent with achievements and the presupposition that there is one with time-span adverbials that accounts for why the latter do not have the same function with achievements as they do with accomplishments. 


\subsection{Progressivity}

A standard objection to the view that achievements denote instantaneous eventualities is the observation that many (though not all) achievements occur in the progressive:

(6) a. Rebecca was reaching the summit when it began to rain.

b. \# Anita was recognizing Peter when I walked in.

c. Astrid was winning the race when we arrived.

d. Are you finding everything okay? 6

e. We visited the wounded soldier, who was dying.

Surely, the objection goes, progressive clauses do not describe instantaneous eventualities, hence the compatibility of the progressive with achievements strongly suggests that latter do not describe instantaneous eventualities either.

The occurrence of achievements in the progressive is indeed a puzzle, but it alone does not constitute a counterexample to the claim that achievements denote instantaneous eventualities unless an analysis is offered of the progressive with achievements that is incompatible with this claim. I know of no such analysis. In fact, I believe that it is possible to turn the tables and use the compatibility of the progressive with achievements (when it is compatible) as further support for the claim that achievements form an aspectual category in their own right.

A largely underappreciated point about achievements in the progressive is that there is always an unpredictable meaning shift implicated. Some achievements appear so often in the progressive that it is hard to see this unpredictable shift at first, yet I claim that it is nevertheless present. Consider the examples in (6). In (6a), was reaching may be paraphrased as 'was approaching': it is not the actual attainment of the summit that was in progress. In (6c), was winning the race has 'was ahead in the race' as a paraphrase-the winning itself was clearly not in progress. The question in (6d) may be rephrased as "Is your search for what you are looking for going well?'. Again, it is not the eventuality described by the achievement (here: a finding) that is in progress. Finally, was dying in (6e) may be paraphrased as 'was suffering and on the verge of death': the death itself was not in progress.

In all of these cases, the eventualities described by the achievements in the progressive are simply not of the same type as the eventualities described by the achievements alone. Furthermore, it is difficult to see how the meaning shifts involved are completely predictable. In each case, there seems to be an element of irreducible lexicalization involved. Why, for example, can we not refer to a captured spy in her final minutes before committing suicide as someone who is dying? If achievements denote instantaneous eventualities, then we do not expect semantically regular progressives to be possible, precisely because eventualities without duration are never in progress.

\subsection{No Partial Completion}

Achievements are incompatible with adverbs expressing that the described eventuality is partially completed or realized:

(7) a. \# Rebecca partly (partially, half, partway, half way) reached the summit. b. \# Anita partly (partially, half, partway, halfway) recognized Peter. 
c. \# Astrid partly (partially, half, partway, halfway) won the race.

d. \# The patient partly (partially, half, partway, halfway) died.

If achievements denote instantaneous eventualities, then this incompatibility is expected: since such eventualities have no proper parts, no partial realization is possible.

Accomplishments, in contrast, typically (although not always) exhibit no conflict with such adverbs:

(8) a. Rebecca partly (partially, half, partway, half way) wrote a letter to the president.

b. Anita partly (partially, half, partway, halfway) proved the theorem.

c. \# The lifeguard partly (partially, half, partway, half way) rescued Peter.

However, even when there is a conflict, as in (8c), the nature of the unacceptability differs from the one in (7). In addition to duration, adverbs like partly, etc. arguably presuppose a certain kind of divisibility for the types of eventualities in question.7 Letters standardly have parts that are written separately; theorems of ten have parts that are proven separately; but people normally do not have parts that are rescued separately (although this is not unimaginable in gruesome accidents). Indeed, a sentence such as Unfortunately, Rebecca only partly rescued her dissertation after it fell out the window sounds unexceptional.

If this line of analysis is correct, then achievements are doubly out, as far as this class of adverbs is concerned: the eventualities that they denote are instantaneous, a fortiori no divisibility of the kind suggested is possible.

\subsection{Intentionality and Manner}

Achievements are incompatible with adverbs expressing that the referent of the subject NP participated intentionally in the described eventuality:

(9) a. \# Rebecca intentionally (attentively, conscientiously, studiously, vigilantly) reached the summit.

b. \# Anita intentionally (attentively, conscientiously, studiously, vigilantly) recognized Peter.

c. \# Astrid intentionally (attentively, conscientiously, studiously, vigilantly) arrived.

In (9a), Rebecca may have intentionally climbed to the summit or even intended to reach it, but her attainment of the summit was not carried out intentionally. Similarly, in (9c), Astrid may have done any number of things leading up to her arrival intentionally, but her very arrival was not performed intentionally.

Perhaps more surprising is the fact that achievements disallow manner adverbs in their eventuality-related interpretation:

(10) a. \# Rebecca quickly (slowly) reached the summit.

b. \# Anita quickly (slowly) recognized Peter.

c. \# Astrid quickly (slowly) won the race.

d. \# The patient died quickly (slowly). 
The intended reading of these sentences is that the eventualities described unfold quickly (slowly) and not that a short (long) period of time elapses before they take place. In (10a), Rebecca may have been quick (slow) to reach the summit, but this crucially pertains to how quickly (slowly) she climbed and not to the reaching itself. Likewise, in (10d), the patient's condition may have quickly (slowly) deteriorated before resulting in death, but the death itself was neither quick nor slow.

The idea that achievements denote instantaneous eventualities can be used to shed light on such data. Intuitively, it is reasonable to think that any sort of intentional activity or act takes time, if only a short time. Since instantaneous eventualities have zero duration, they lack the temporal extent required for intentional activity. The lack of a temporal extent also accounts for why instantaneous eventualities cannot be judged as quick or slow: it is simply a category mistake to assert of durationless eventualities that they are quick or slow, because quickness and slowness presuppose a variability in temporal extent that instantaneous eventualities necessarily lack.

\section{Boundaries in an Event Semantics}

Achievements have suffered an undeniable neglect in the aspectual literature. They receive no treatment in Krifka (1989), which is otherwise the most explicit event semantic account of aspect to date. This omission is ironic, for we might have expected event semantics (of all approaches) to have delivered an analysis of achievements. There is also a marked tendency for achievements to be assimilated to accomplishments, only to be ignored (Parsons (1990, p. 24), Verkuyl (1993, §2.4)).

More promising in this regard are approaches that recognize achievements as an aspectual category in their own right. This is true of Dowty's (1979) original analysis of achievements in terms of the BECOME-operator, C. S. Smith's (1991) two-component aspectual theory, and Naumann's (1995) recent analysis of aspectual composition in dynamic logic. However, in none of these accounts do achievements actually denote properties of instantaneous objects (whether of instants or instantaneous eventualities). Upon closer inspection, achievements in fact denote 'minimal' (non-singleton) intervals or transitions, i.e., objects that-although short-nonetheless have a duration. Consequently, the intuitive 'instantaneity of achievements' gets lost in the technical implementation, and achievements turn out to be just short accomplishments.

Another school speaks of achievements as denoting 'culmination points' or 'culminations' (e.g., Moens und Steedman (1988), Kamp und Reyle (1993, $\S 5.3 .2)$ ). Binnick (1991, p. 195) puts this view best:

An achievement is all culmination; though the achievement is possibly preceded by some activity (spotting something is preceded by looking for it), the verb refers only to the achievement phase, not to the preceding activity.

However, apart from the unhappy term 'culmination', which is biased towards endings, whereas achievements may also denote beginnings (e.g., recognize, as I suggested in section 1), the more serious worry about this kind of analysis is that models for achievements with 'culminations' have never been proposed.

The perspective that I advocate is to analyze achievements as denoting (left or right) boundaries of eventualities. Pianesi and Varzi (1994, pp. 533, 544) 
mention in passing the idea of analysing achievements as denoting right boundaries of eventualities, but they do not motivate or develop it further. In fact, they do not present a semantics for achievements. (But this was also not their goal in that paper.)

My approach is inspired by work on mereotopology (e.g., Pianesi and Varzi (1994), B. Smith (to appear)), but I consider it also to be in tune with Galton's (1994) positive attitude towards instantaneous events and Mittwoch's (1991) appreciation of achievements.

\subsection{Temporal Ontology}

The leading idea is that there are two basic sorts of eventualities, happenings and boundary happenings. Happenings consist of events, processes, and states, i.e., roughly comparable to the usual assortment of eventualities familiar from an unsorted event semantics. ${ }^{8}$ I say 'roughly comparable' because a condition that I place on happenings is that they be self-connected (Ax 14 in section 3.1.2). Consequently, although every happening is an eventuality, not every eventuality is a happening. Boundary happenings, in contrast, consist of the boundaries of happenings. Taken together, happenings and boundary happenings constitute the domain of basic eventualities.

As a aid to intuition, I make occasional use of 'bounded interval' diagrams like the one in (11), where $z$ is a happening, $y$ is the right boundary happening of $z$, and $x$ is the body of $z$ (i.e., $x$ is $z$ stripped of its left and right boundary happenings). For perspicuity, $x$ and $y$ are abstracted and enlarged. What remains implicit in (11) is the left-to-right linear structure of time.

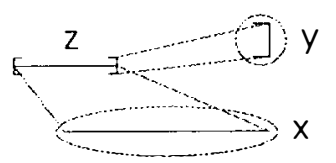

Not reflected in (11) is the possibility of constructing other eventualities from happenings. Suppose that we have two disjoint happenings, $x$ and $y$, separated by a gap, such that $x$ is earlier than $y$, and imagine that we 'add' them together, as in (12). The result, $z$, is a complex eventuality that is built out of happenings but which at the same time is not itself a happening. (Recall that happenings are required to be gapless and that $x$ and $y$ are separated by a gap.)

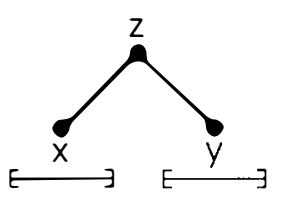

We aim to bring four theories together in the formal account. The first is a theory of parts (or mereology). Insofar as eventualities may be parts of others, a theory of this relation is indispensable. The second is a theory of linear order. Eventualities are temporally ordered, and insofar as we need to make reference to the earlier and later parts of an eventuality, we cannot do without a linear order. The third is a theory of times. This is needed because we want to distinguish purely 
temporal overlap among eventualities (sharing of a time) from their mereological overlap (sharing of a part). Last but not least, the fourth is a theory of eventualities, the main protagonists of the story. In the present context, this means that we require a theory of the two basic sorts, happenings and boundary happenings. It goes without saying that I cannot do justice to all of the complexities resulting from this four-way interaction here, but the account that I propose is guided by these considerations.

The temporal ontology is formalized in a second-order predicate logic with identity, $\imath$-descriptions, and the $\lambda$-operator. In addition, some means of handling non-referring expressions is assumed. Although the exact choice of ontological primitives is somewhat flexible, for concreteness I settle on the following domains and relations together with their designated predicates: 9

- a set of happenings (h)

- a set of boundary happenings $\left(\mathrm{b}_{\mathrm{h}}\right)$

- a set of intervals (i)

- a set of points $(\mathrm{P})$

- a precedence relation $(<)$

- a proper part relation (ᄃ)

In what follows, the unsorted variables $\mathrm{x}, \mathrm{y}, \mathrm{z} \ldots$ range over all objects of the ontology, which includes not only happenings, boundary happenings, intervals, and points, but also physical objects (which, however, I do not explicitly discuss). While I do not rule out the existence of 'mixed' objects that have (say) intervals and physical objects as parts, I do assume that for something to count as a temporal object, it must be built out of happenings, boundary happenings, intervals, or points (Df 10). In other words, the temporal ontology is grounded in these four basic types of objects.

\subsubsection{Definitions}

To start things off, let us define the domain of basic eventualities as comprised of happenings and boundaries, and that of basic times as comprised of intervals and points:

Df1. Basic-Ev $:=\lambda x\left(h(x) \vee b_{h}(x)\right) \quad(x$ is a basic eventuality $)$

Df2. Basic-Tm $:=\lambda x(i(x) \vee p(x)) \quad$ ( $x$ is a basic time)

Turning to the mereological definitions, we say that an object without proper parts is an atom:

Df3. Atom : $=\lambda x(\neg \exists y(y \sqsubset x))$

( $x$ is an atom)

The (improper) part and overlap relations are defined in the usual manner:

Df4. $\quad \sqsubseteq:=\lambda x \lambda y(x \sqsubset y \vee x=y)$

Df5. $\quad \circ:=\lambda x \lambda y(\exists z(z \sqsubseteq x \wedge z \sqsubseteq y))$

( $x$ is part of $y$ ) ( $x$ and $y$ overlap) 
The two sum operations, general and binary, then receive the following definitions (where $\mathrm{X}$ in Df6 is a one-place predicate variable):

$\begin{array}{llr}\text { Df6. } & \sigma:=\lambda X \imath y\left(\forall z\left(z^{\circ} y \leftrightarrow \exists z^{\prime}\left(X\left(z^{\prime}\right) \wedge z^{\prime} \circ z\right)\right)\right) & \begin{array}{r}\left.\text { (general sum of } X^{\prime} s\right) \\ \text { (binary sum of } x \text { and } y)\end{array}\end{array}$

With the sum operation at our disposal, we can define three relevant sorts of temporal objects: (i) those built out of basic eventualities, (ii) those built out of basic times, and (iii) those built out of basic eventualities or basic times (or both).

$\begin{array}{llr}\text { Df8. } & \text { Ev }:=\lambda x(x=\sigma(\lambda y(y \sqsubseteq x \wedge \operatorname{Basic}-\operatorname{Ev}(y)))) & (x \text { is an eventuality }) \\ \text { Df9. } & \operatorname{Tm}:=\lambda x(x=\sigma(\lambda y(y \sqsubseteq x \wedge \operatorname{Basic}-\operatorname{Tm}(y)))) & (x \text { is a time }) \\ \text { Df 10. } & \text { Temp-Obj }:=\lambda x(x=\sigma(\lambda y(y \sqsubseteq x \wedge(\operatorname{Ev}(y) \vee \operatorname{Tm}(y))))) & \end{array}$

$(x$ is a temporal object)

A couple of additional mereological operations prove to be useful. The binary product of two objects is the largest object in their overlap, and the difference of two objects is the result of removing all of the parts of the second from the first.

Df11. $\otimes:=\lambda x \lambda y z z\left(z=\sigma\left(\lambda z^{\prime}\left(z^{\prime} \sqsubseteq x \wedge z^{\prime} \sqsubseteq y\right)\right)\right) \quad$ (binary product of $x$ and $y$ ) Df12. $\quad-:=\lambda x \lambda y 1 z\left(z=\sigma\left(\lambda z^{\prime}\left(z^{\prime} \sqsubseteq x \wedge \neg\left(z^{\prime} \circ y\right)\right)\right)\right.$ ) (difference of $x$ and $y$ )

It is possible to mimic certain mereological relations using the precedence relation. Two temporal objects cross when neither precedes the other-this is the analogue of overlap. An object is (improperly) enclosed in another if everything that crosses the first also crosses the second. Here we have the analogue of (improper) part. The proper enclosure relation is an asymmetric restriction of enclosure. It evidently corresponds to proper part. Finally, coincidence arises whenever two objects are enclosed in each other (mereologically, this amounts to identity).

Df13. Cross : $=\lambda \times \lambda y(\neg(x<y) \wedge \neg(y<x)) \quad$ ( $x$ and $y$ cross)

Df14. Encl $:=\lambda x \lambda y(\forall z(\operatorname{Cross}(z, x) \rightarrow \operatorname{Cross}(z, y))) \quad(x$ is enclosed in $y)$

Df15. Prop-Encl := $\quad \lambda x \lambda y(\operatorname{Encl}(x, y) \wedge \neg \operatorname{Encl}(y, x))$

Df16. Coin $:=\lambda x \lambda y(\operatorname{Encl}(x, y) \wedge \operatorname{Encl}(y, x)) \quad(x$ is properly enclosed in $y)$

Bear in mind that these are temporal and not mereological relations. Happenings and intervals, given that they are different sorts of objects, may not overlap mereologically. But they may cross. And they may even coincide. The latter obtains whenever the time of a happening exactly matches an interval. The possibility of this match suggests a way of using coincidence to define the temporal trace function:

Df17. $\tau:=\lambda \operatorname{xly}(\operatorname{Ev}(x) \wedge \operatorname{Tm}(y) \wedge \operatorname{Coin}(x, y)) \quad$ (temporal trace of $x$ )

The temporal trace function maps eventualities to the times that they coincide with.

We can distinguish two important ways in which temporal objects overlap. In order to state them, we first group boundary happenings and points together as thin objects:

Df 18. Thn $:=\lambda x\left(b_{h}(x) \vee p(x)\right)$

$(x$ is thin) 
Two objects are externally connected whenever their product is thin.10 By comparison, they are internally connected whenever they overlap but are not externally connected.

Df 19. Ex-Cn: $=\lambda x \lambda y(\exists z(\operatorname{Thn}(z) \wedge z=x \otimes y))(x$ and $y$ are externally connected $)$ Df20. In-Cn:= $\quad \lambda x \lambda y\left(x^{\circ} y \wedge \neg E x-C n(x, y)\right) \quad(x$ and $y$ are internally connected $)$

An object is self-connected if every way of splitting it into two results in overlapping objects:

Df21. Self-Cn: $=\lambda x\left(\forall y \forall z\left(x=y \oplus z \rightarrow y^{\circ} z\right)\right) \quad(x$ is self-connected $)$

Many temporal objects that are not self-connected are nevertheless made up of selfconnected objects. We saw such an example in (12), where the happenings $x$ and $y$ are self-connected but their sum $z$ is not. Let us say that an object is a maximally self-connected part of another when it is self-connected and there is no intermediate part properly containing it that is self-connected. In (12) both $x$ and $y$ are maximally self-connected parts of $z$.

Df22. Max-Self-Cn := $\lambda x \lambda y($ Self-Cn(x) $\wedge x \sqsubseteq y \wedge \neg \exists z(x \sqsubset z \wedge z \sqsubseteq y \wedge$ Self-Cn(z)) ( $\quad(x$ is a maximally self-connected part of $y$ )

Temporal objects, if they are not atoms, have distinct earlier and later parts. In the case of self-connected objects, an object is a left part of another if no other part precedes it, and it is a right part if no other part follows it. However, in order to allow for objects that are not self-connected, we relativize the definitions of left part and right part to maximally self-connected parts:

$$
\begin{aligned}
& \text { Df23. Lf: }=\lambda x \lambda y\left(\exists z\left(x \sqsubseteq z \wedge \operatorname{Max}-\operatorname{Self}-C n(z, y) \wedge \forall z^{\prime}\left(z^{\prime} \sqsubseteq z \rightarrow \neg\left(z^{\prime}<x\right)\right)\right)\right. \\
& (x \text { is a left part of } y) \\
& \text { Df24. Ri : }=\lambda x \lambda y\left(\exists z\left(x \sqsubseteq z \wedge \operatorname{Max}-\operatorname{Self}-C n(z, y) \wedge \forall z^{\prime}\left(z^{\prime} \sqsubseteq z \rightarrow \neg\left(x<z^{\prime}\right)\right)\right)\right. \\
& (x \text { is a right part of } y)
\end{aligned}
$$

According to Df23, for example, both the first half of $x$ and the first half of $y$ in (12) are left parts of $z$.

In order to generalize over happenings and intervals, we collect them together as thick objects:

Df25. Thk := $\lambda x(h(x) \vee i(x)) \quad(x$ is thick)

An object is a boundarypart of another whenever the first is thin, the second has a thick part, and the first is part of that thick object:

Df26. $\quad B d:=\lambda x \lambda y(\operatorname{Thn}(x) \wedge \exists z(\operatorname{Thk}(z) \wedge x \sqsubseteq z \wedge z \sqsubseteq y))$

( $x$ is a boundary part of $y$ )

Combining definitions, we can say when one object is a left boundary part or a right boundary part of another: 
Left and right boundary parts are in general not unique. We saw this already in (12), where the left (right) boundary parts of $x$ and $y$ each count as a left (right) boundary part of $z$ according to Df 27 (Df28). In order to obtain unique boundaries, we have to consider sums. The left boundary of a temporal object is the sum of its left boundary parts, its right boundary is the sum of its right boundary parts, and its boundary as a whole is the sum of the left and right boundaries. These notions are formalized as follows:

Df29. $\quad \beta_{\mathrm{Lf}}:=\lambda \times \operatorname{xly}(\mathrm{Y}=\sigma(\lambda z(\operatorname{Lf}-\mathrm{Bd}(\mathrm{z}, \mathrm{x}))))$

Df30. $\quad \beta_{R i}:=\lambda x l y(y=\sigma(\lambda z(R i-B d(z, x))))$

Df31. $\quad \beta:=\lambda x \operatorname{ly}\left(y=\beta_{L f}(x) \oplus \beta_{R i}(x)\right)$

(left boundary of $x$ )

(right boundary of $x$ )

(boundary of $x$ )

In the present analysis, if a temporal object has a boundary, then the boundary is part of it - this is ultimately due to the very definition of a boundary part in Df26. In the axiomatic treatment to follow, in fact, all thick objects have boundaries (Ax15). Even so, nothing prevents us from taking a bounded object and mereologically subtracting its boundary. The result of doing so is its body (' $\kappa$ ' in Df 32 is mnemonic for Körper). ${ }^{11}$

Df32. $\quad \kappa:=\lambda x \iota y(y=x-\beta(x))$

(body of $x$ )

Using the notion of a body, we define the immediate precedence relation, which basically states that one object immediately precedes another whenever the two are externally connected and the body of the first precedes the body of the second. However, in order to allow for intervals and happenings to immediately precede each other, given that these are never externally connected, a slight complication in the definition is necessary. Specifically, we have to consider the temporal trace of an eventuality whenever it immediately precedes or follows a time.

Df33.

$$
\begin{aligned}
& \ll:=\lambda x \lambda y(\kappa(x)<\kappa(y) \wedge(\operatorname{Ex}-C n(x, y) \vee \operatorname{Ex}-C n(\tau(x), y) \vee \\
&\operatorname{Ex}-C n(x, \tau(y)))) \\
&(x \text { immediately precedes } y)
\end{aligned}
$$

Effectively, only bounded objects may immediately precede each other. This is because $\kappa$ is not defined for objects without boundaries. Since neither bodies nor thin objects have boundaries, immediate precedence is not defined for them.

\subsubsection{Axioms}

The axioms of the temporal ontology serve to regulate the behavior of its primitive objects and relations. While the proposed set of axioms may not be free of every redundancy, I have nevertheless endeavored to keep them economical.

To begin with, we require that the domain of temporal objects not be empty. The first axiom, which guarantees the existence of a happening, fulfills this requirement:

Ax1. $\quad \exists x(h(x))$ (there is a happening) 
The following three axioms stipulate that the proper part relation is a strict partial order without a bottom element:
Ax2.
$\forall x(\neg(x \sqsubset x))$
Ax3. $\quad \forall x \forall y \forall z((x \sqsubset y \wedge y \sqsubset z) \rightarrow x \sqsubset z)$
Ax4. $\quad \forall x \forall y\left(x \sqsubset y \rightarrow \exists z\left(z \sqsubset y \wedge \neg\left(z^{\circ} x\right)\right)\right)$
(irreflexivity of proper part)
(transitivity of proper part)
(witness for proper part)

It was noted above in connection with Df 6 that it is one thing to know what a general sum is and quite another to know whether any exist. Ax5 asserts that nonempty sets of objects have sums:

$\forall X(\exists y(X(y)) \rightarrow \exists y(Y=\sigma(X))) \quad$ (existence of general sums)

These axioms suffice to give the mereology the strength of a complete boolean algebra without a zero element.

The axioms for the precedence relation are a bit more cumbersome to state, because now we cannot completely ignore the sortal distinctions of the ontology. Since the precedence relation is intended to be temporal precedence, it is natural that it should hold only among temporal objects (and not among physical or 'mixed' objects):

Ax6.

$$
\begin{array}{r}
\forall x \forall y(x<y \rightarrow(\operatorname{Temp}-O b j(x) \wedge \text { Temp-Obj(y))) } \\
\text { (precedence holds among temporal objects) }
\end{array}
$$

That the precedence relation is a strict partial order is valid for all temporal objects:

$$
\begin{array}{llr}
\text { Ax7. } & \forall x(\neg(x<x)) & \text { (irreflexivity of precedence) } \\
\text { Ax8. } & \forall x \forall y \forall z((x<y \wedge y<z) \rightarrow x<z) & \text { (transitivity of precedence) }
\end{array}
$$

The domain of times, in particular, is linear. This principle rules out the possibility of distinct parallel times. Since times are built up out of basic times, it suffices to state the principle for the latter:

Ax9. $\quad \forall x \forall y(($ Basic-Tm $(x) \wedge$ Basic-Tm $(y)) \rightarrow(x<y \vee y<x \vee x \circ y))$ (linearity)

Finally, atomic points satisfy density, which asserts that between any two atomic points there is a third atomic point.

Ax10. $\quad \forall x \forall y((p(x) \wedge p(y) \wedge \operatorname{Atom}(x) \wedge \operatorname{Atom}(y)) \rightarrow$

$$
(x<y \rightarrow \exists z(x<z \wedge z<y \wedge p(z) \wedge \text { Atom( }(z)))) \quad \text { (density for points) }
$$

The precedence relation on atomic points is a dense linear order.

The connection between mereology and temporal precedence is revealed by inclusion. Essentially, if one temporal object is a proper part of another, then the first is also properly enclosed in the second (Df 14).

Ax11. $\quad \forall x \forall y((T e m p-O b j(x) \wedge$ Temp-Obj(y)) $\rightarrow$ $(x \sqsubset y \rightarrow \operatorname{Prop}-\operatorname{Encl}(x, y)))$

(inclusion) 
The next axiom guarantees that the domain of times is open: for every atomic point, there are two intervals that intersect at exactly that point.

Ax 12. $\quad \forall x((p(x) \wedge \operatorname{Atom}(x)) \rightarrow \exists y \exists z(i(y) \wedge i(z) \wedge x=y \otimes z)) \quad$ (openness)

There is still no direct connection enforced between eventualities and times. We change this with the next axiom, which requires every basic eventuality to have a basic time as its temporal trace:

Ax 13. $\quad \forall x($ Basic-Ev $(x) \rightarrow \exists y(B a s i c-\operatorname{Tm}(y) \wedge \tau(x)=y))$

(basic eventualities require basic times)

Since a hallmark of the present approach is the proclaimed distinction between thick and thin objects, we should guarantee that there really is such a distinction. Let us begin with three crucial properties of thick objects: $(i)$ they are self-connected (Df21), (ii) they have boundaries (Df31), and (iii) they are dense.

Ax 14. $\quad \forall x(\operatorname{Thk}(x) \rightarrow$ Self-Cn(x)) (thick objects are self-connected)

Ax 15. $\quad \forall x(\operatorname{Thk}(x) \rightarrow \exists y(y=\beta(x))) \quad$ (thick objects have boundaries)

Ax16. $\quad \forall x(\operatorname{Thk}(x) \rightarrow \exists y \exists z(\neg(y=z) \wedge \operatorname{Thk}(y) \wedge \operatorname{Thk}(z) \wedge x=y \oplus z))$

(thick objects are dense)

Observe that density for thick objects is very different from density for atomic points (Ax 10). The density of thick obejcts entails that any thick object is the sum of two distinct thick objects. Consequently, no thick object is an atom. 12

A question not addressed by these axioms concerns the upward closure conditions for thick objects. Here we have to treat happenings separately from intervals. For intervals, the matter is fairly straightforward. It is reasonable to say that the sum of any two overlapping intervals is again an interval:

Ax 17. $\forall x((i(x) \wedge i(y) \wedge x \circ y) \rightarrow i(x \oplus y)) \quad$ (upward closure for intervals)

For happenings, we base the condition on internal connection (Df20), which effectively requires that a thick object be part of the overlap. In other words, if two happenings are internally connected, then their sum is a happening:

$$
\text { Ax 18. } \forall x \forall y\left((h(x) \wedge h(y) \wedge \ln -C n(x, y)) \rightarrow \begin{array}{l}
h(x \oplus y)) \\
\text { (upward closure for happenings) }
\end{array}\right.
$$

Thin objects are more straightforward to treat than thick objects. They exhibit two important features. The first is that they are boundary parts of thick objects; the second is that the property of being thin is homogeneous: not only is every thin object the sum of atomic thin objects, but also every sum of atomic thin objects is thin.

$$
\begin{aligned}
& \text { Ax 19. } \forall x(\operatorname{Thn}(x) \rightarrow \exists y(\operatorname{Bd}(x, y))) \\
& \text { Ax20. } \forall x(\operatorname{Thn}(x) \leftrightarrow x=\sigma(\lambda y(\operatorname{Thn}(y) \wedge \operatorname{Atom}(y) \wedge y \sqsubseteq x))) \\
& \text { (homogeneity of thinness) }
\end{aligned}
$$


Another way of describing the import of Ax20 is that we can never get a thick object by adding together thin ones. Note that not all thin objects are self-connected. For example, although all boundaries are thin, they are typically not self-connected, as we have seen.

This concludes my presentation of the axioms of the temporal ontology. Additional axioms are imaginable, yet this collection gives a fairly clear picture of the intended objects and their relations. Due to lack of space, I postpone a discussion of theorems of the ontology to another occasion and turn immediately to the semantics of achievements.

\subsection{Achievements}

I claimed in section 1 that the logic of achievements is the logic of beginnings and endings. Consequently, in order to offer an analysis of achievements, I have to say what beginnings and endings are. At first glance, it might appear that beginnings and endings are just left boundary parts (Df27) and right boundary parts (Df28), respectively. But this, it turns out, is not enough: beginnings and endings, unlike left and right boundaries, require reference to the types of eventualities that they are boundaries of.

We say that a boundary happening begins (ends) an eventuality of type $X$ just in case there is no eventuality immediately preceding (following) it such that the sum of the two eventualities is of type $X$ :

Df34.

$$
\begin{gathered}
\text { Beg : }=\lambda x \lambda y \lambda X\left(b_{h}(x) \wedge E v(y) \wedge L f-B d(x, y) \wedge X(y) \wedge\right. \\
\neg \exists z(z \ll y \wedge X(z \oplus y))) \\
\text { (boundary happening } x \text { begins eventuality } y \text { of type } X) \\
\begin{array}{c}
\text { End }:=\lambda x \lambda y \lambda X\left(b_{h}(x) \wedge E v(y) \wedge \operatorname{Ri}-B d(x, y) \wedge X(y) \wedge\right. \\
\neg \exists z(y \ll z \wedge X(z \oplus y))) \\
\text { (boundary happening } x \text { ends eventuality } y \text { of type } X)
\end{array}
\end{gathered}
$$

Df35.

Recall that since left (right) boundary parts are always parts of thick objects, $x$ in Df34 (Df35) is in fact part of a happening that is contained in $y$. The difference between beginnings (endings) and left (right) boundary parts is not that the former are not instances of the latter (they are), but rather that the former introduce more descriptive content than the latter. More succinctly, beginnings (endings) are left (right) boundary parts under a description of what they bound.

In presenting a semantics for achievements, it is convenient (although not absolutely essential) to assume a theory of thematic relations. I take it that such a theory provides a small set of thematic relations that specifies the general ways in which objects may participate in eventualities. I define this set disjunctively in Df36, where the '...' betrays an uncertainty regarding the exact inventory of relations.

Df36. Thematic $:=\lambda R(R=$ Agent $\vee R=$ Experiencer $\vee R=$ Theme $\vee$
$R=$ Patient $\vee \ldots)$
$(R$ is a thematic relation $)$

Among the principles that a theory of thematic relations should validate in the present context is one which affirms that thematic relations hold between happenings and objects that participate in those happenings. Observe that $\mathrm{Ax} 21$ 
leaves open the sortal character of the right argument of thematic relations, which may also be a happening (e.g., The picnic took place at noon):

Ax21. $\quad \forall R($ Thematic $(R) \rightarrow \forall x \forall y(R(x, y) \rightarrow h(x)))$

(left argument of thematic relations is a happening)

However, the real import of Ax21 is that only happenings have participants. If a complex (i.e., non-basic) eventuality has participants, they may be identified with the participants of the happenings that make it up. In other words, complex eventualities have participants in virtue of the participants that their component happenings have. Boundary happenings, in contrast, have no participants. How could one participate in a durationless eventuality? The difficulty of giving an intelligible answer to this question suggests that the treatment of boundary happenings as fundamentally different from happenings is on the right track.

The paper concludes with a number of semantic derivations involving achievements. In each case, tense is ignored and a predicate of boundary happenings is derived that syntactically corresponds to a (subject-internal) VP. The semantic composition throughout is driven by functional application.

The first example illustrates the achievement aspectualizer begin with $V$-ing as its complement:

(13) Rebecca began climbing.

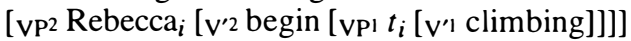

a. $\quad$ begin $\Rightarrow \lambda X \lambda y(\exists z(\operatorname{Beg}(y, z, X)))$

climbing $\Rightarrow \lambda y^{\prime} \lambda x^{\prime}\left(C \operatorname{limb}\left(x^{\prime}\right) \wedge h\left(x^{\prime}\right) \wedge \operatorname{Agent}\left(x^{\prime}, y^{\prime}\right)\right)$

Rebecca $\Rightarrow$ Rebecca

$t \Rightarrow Z^{\prime}$

b. $\quad\left[\mathrm{vP}^{1} t_{i}\left[\mathrm{v}^{\prime} \mathrm{l}\right.\right.$ climbing] $\Rightarrow \lambda \mathrm{x}^{\prime}\left(\mathrm{Climb}\left(\mathrm{x}^{\prime}\right) \wedge \mathrm{h}\left(\mathrm{x}^{\prime}\right) \wedge \operatorname{Agent}\left(\mathrm{x}^{\prime}, \mathrm{z}^{\prime}\right)\right)$

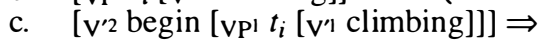

$\lambda y\left(\exists z\left(\operatorname{Beg}\left(y, z, \lambda x^{\prime}\left(\operatorname{Climb}\left(x^{\prime}\right) \wedge h\left(x^{\prime}\right) \wedge \operatorname{Agent}\left(x^{\prime}, z^{\prime}\right)\right)\right)\right)\right)$

d. [vP2 Rebecca ${ }_{i}\left[v^{\prime 2}\right.$ begin [vP1 $t_{i}\left[v^{\prime}\right.$ climbing] ] ] $\Rightarrow$

$\lambda y\left(\exists z\left(\operatorname{Beg}\left(y, z, \lambda x^{\prime}\left(C \operatorname{limb}\left(x^{\prime}\right) \wedge h\left(x^{\prime}\right) \wedge\right.\right.\right.\right.$ Agent( $x^{\prime}$, Rebecca)) )))

Observe that begin is treated as a raising verb. The transition from (13c) to (13d) requires $\lambda$-abstraction of the free variable $z^{\prime}$. The resulting formula in (13d) is a predicate of boundary happenings that begin a happening in which Rebecca climbs.

For the sake of comparison, I also give an instance of the weather verb rain as the complement of begin:

$$
\text { It began raining. }
$$

a. raining $\Rightarrow \lambda x^{\prime}\left(\right.$ Rain $\left.\left(x^{\prime}\right) \wedge h\left(x^{\prime}\right)\right)$

b. $\quad\left[\mathrm{VP}^{2} \mathrm{It}_{i}\left[\mathrm{v}^{\prime 2}\right.\right.$ begin [VP1 $t_{i}\left[\mathrm{v}^{\prime}\right.$ raining] $\left.]\right] \Rightarrow$

$$
\lambda y\left(\exists z\left(\operatorname{Beg}\left(y, z, \lambda x^{\prime}\left(\operatorname{Rain}\left(x^{\prime}\right) \wedge h\left(x^{\prime}\right)\right)\right)\right)\right)
$$

Here neither $i t$ nor its trace receives an interpretation. The formula in (14b) is a predicate of boundary happenings that begin a happening of raining.

The next example shows how the relation Beg can be applied in the analysis of recognize, a more canonical achievement verb: 
Anita recognized Peter.

[vP Anita [v' recognize [NP Peter]]]

a. $\quad$ recognize $\Rightarrow$

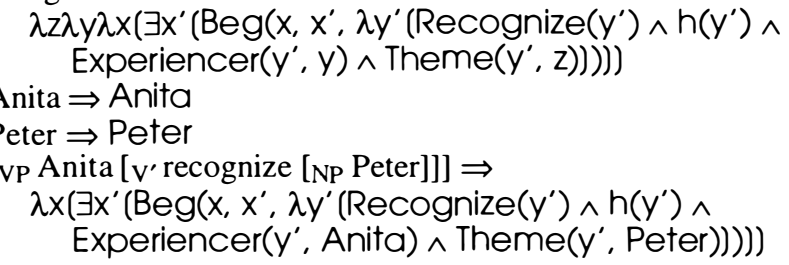

The predicate Recognize in (15a), a predicate of happenings, represents the stative verb recognize. The formula in (15b) is a predicate of boundary happenings that begin a (state) happening in which Anita recognizes Peter. Notice that the salient difference between begin and recognize is that the latter lexically specifies the type of happenings that the denoted boundary happenings are left boundaries of.

For an example involving the relation End, consider the achievement aspectualizer stop taking $V$-ing as its complement:

\section{Rebecca stopped climbing.}

a. $\quad$ stop $\Rightarrow \lambda X \lambda y(\exists z(E n d(y, z, X)))$

b. $\quad\left[\mathrm{vP}^{2} \operatorname{Rebecca}_{i}\left[\mathrm{v}^{\prime 2}\right.\right.$ stop [vP1 $t_{i}\left[\mathrm{v}^{\prime}\right.$ climbing $\left.\left.\left.]\right]\right]\right] \Rightarrow$ $\lambda y\left(\exists z\left(\operatorname{End}\left(y, z, \lambda x^{\prime}\left(\mathrm{Climb}\left(x^{\prime}\right) \wedge h\left(x^{\prime}\right) \wedge\right.\right.\right.\right.$ Agent( $x^{\prime}$, Rebecca)) )))

Comparing the analyses in (13) and (16), we see that stop is the inverse of begin. The formula in (16b) is a predicate of boundary happenings that end a happening in which Rebecca climbs.

Many achievement verbs denote beginnings as well as endings. As suggested in section 1, one such example is reach: if Rebecca reaches the summit, then the reaching is both the ending of her climb and the beginning of her being at the summit. I detail this in the next derivation:

Rebecca reached the summit.

a. reach $\Rightarrow$

$$
\begin{gathered}
\lambda z \lambda y \lambda x\left(\exists x ^ { \prime } \left(\operatorname { E n d } \left(x, x^{\prime}, \lambda y^{\prime}\left(\text { Motion }\left(y^{\prime}\right) \wedge h\left(y^{\prime}\right) \wedge\right.\right.\right.\right. \\
\text { Agent } \left.\left.\left(y^{\prime}, y\right) \wedge \text { Goal }\left(y^{\prime}, z\right)\right)\right) \wedge \\
\exists x^{\prime \prime}\left(\operatorname { B e g } \left(x, x^{\prime \prime}, \lambda y^{\prime \prime}\left(B e-O n\left(y^{\prime \prime}\right) \wedge h\left(y^{\prime \prime}\right) \wedge\right.\right.\right. \\
\text { Theme } \left.\left.\left.\left.\left(y^{\prime \prime}, y\right) \wedge \text { Location }\left(y^{\prime \prime}, z\right)\right)\right)\right)\right)
\end{gathered}
$$

the summit $\Rightarrow 1 z^{\prime}$ (summit( $\left.z^{\prime}\right)$ )

b. [vP Rebecca [ $v^{\prime}$ reach [NP the summit]]] $\Rightarrow$

$$
\begin{gathered}
\lambda x\left(\exists x ^ { \prime } \left(\text { End } \left(x, x^{\prime}, \lambda y^{\prime}\left(\text { Motion }\left(y^{\prime}\right) \wedge h\left(y^{\prime}\right) \wedge\right.\right.\right.\right. \\
\text { Agent } \left.\left.\left(y^{\prime}, \text { Rebecca) } \wedge \text { Goal }\left(y^{\prime}, i z^{\prime}\left(\operatorname{summit}\left(z^{\prime}\right)\right)\right)\right)\right)\right) \wedge \\
\exists x^{\prime \prime}\left(\operatorname { B e g } \left(x, x^{\prime \prime}, \lambda y^{\prime \prime}\left(\operatorname{Be}-A t\left(y^{\prime \prime}\right) \wedge h\left(y^{\prime \prime}\right) \wedge\right.\right.\right. \\
\text { Theme }\left(y^{\prime \prime}, \text { Rebecca) } \wedge\right. \\
\text { Location } \left.\left.\left.\left.\left(y^{\prime \prime}, z^{\prime}\left(\operatorname{summit}\left(z^{\prime}\right)\right)\right)\right)\right)\right)\right)
\end{gathered}
$$

The formula in (17b) is a predicate of boundary happenings that both end a happening in which Rebecca climbs to the summit and begin a (state) happening in which she is at the summit. Strictly speaking, reach entails not a climbing but only a prior 
motion happening. In this example, however, we may grant that the motion happening is a climbing.

\section{Endnotes}

* Earlier versions of this paper were presented at Sinn und Bedeutung at Universität Tübingen on 21 December 1996 and at SALT VII at Stanford University on 23 March 1997. Those two audiences have helped me with their questions and I thank Manfred Bierwisch, Tim Fernando, Hans Kamp, Ralf Naumann, and Frank Schilder for more detailed exchanges. I am especially grateful to Ralf Naumann for a number of useful discussions about achievements. Naturally, no one else necessarily agrees with what I have written here. This paper is based upon work supported by the North Atlantic Treaty Organization under a Grant awarded in 1996 and by the Deutsche Forschungsgemeinschaft (Sonderforschungsbereich 282, Teilprojekt D3). Reactions are welcome at: pinon@phil-fak.uni-duesseldorf.de

1. The assumption is reasonable. Given that instants have zero duration, it is in fact difficult to imagine how something could change in no time at all. This view is corroborated by models of changes as relations between states (i.e., as state transformers), which are currently used in computer science: a particular state cannot both hold and not hold at an instant.

2. Note that recognize is ambiguous between an achievement and a state, as is shown by Since Anita finally recognized Peter five minutes ago, she certainly recognizes him now. Although I only discuss the syntactic frame recognize + NP, this aspectual ambiguity is also present in the frame recognize + CP (cf. I suddenly recognized that my analysis had problems vs. I recognize that my analysis has problems).

3. The term 'eventuality' stems from Bach (1981) and has the same extension as 'situation' in Mourelatos (1981), i.e., as 'event' in the broad sense.

4. Because of aspectual composition, an achievement at the V-level is not always an achievement at the VP- or IP-level. Consider the contrast between Mary arrived and Guests arrived. The latter but not the former sentence may be interpreted as a complex activity: Guests arrived all day long vs. \# Mary arrived all day long.

5. Actually, the sentences in (5) may have two readings, but the one on which in-adverbials are synonymous with after-adverbials is much less prominent.

6. As asked by a saleswoman in San Diego, CA on 17 March 1997.

7. Not to be identified with divisive reference as discussed in Krifka (1989).

8. See Piñón (1995) for a sorted ontology of events, processes, and states without boundaries.

9. Intervals and points are also known as periods and instants, respectively. Expressions of the logical language are given in this typeface.

10. External connection among intervals in dense time is the correlate of their (nonoverlapping) abutment in discrete time.

11. The body of a bounded object is its topological interior.

12. Landman (1991, p. 175) points out that density conflicts with atomicity in interval structures. 


\section{References}

Bach, Emmon. 1981. On Time, Tense, and Aspect: An Essay in English Metaphysics. Radical Pragmatics, ed. P. Cole, 62-81. New York: Academic Press.

Binnick, Robert I. 1991. Time and the Verb: A Guide to Tense and Aspect. New York: Oxford University Press.

Chisholm, Roderick M. 1982. Beginnings and Endings. Brentano and Meinong Studies (= Studien zur Österreichischen Philosophie 3), 114-124. Amsterdam: Editions Rodopi B.V.

Dowty, David R. 1979. Word Meaning and Montague Grammar. Dordrecht: D. Reidel Publishing Company.

Freed, Alice F. 1979. The Semantics of English Aspectual Complementation. Dordrecht: D. Reidel Publishing Company.

Galton, Antony. 1994. Instantaneous Events. Temporal Logic: Proceedings of the ICTL Workshop, ed. H. J. Ohlbach, 4-11. Saarbrücken: Max-PlanckInstitut für Informatik, Technical Report MPI-I-94-230.

Kamp, Hans, and Uwe Reyle. 1993. From Discourse to Logic. Dordrecht: Kluwer Academic Publishers.

Krifka, Manfred. 1989. Nominalreferenz und Zeitkonstitution: Zur Semantik von Massentermen, Pluraltermen und Aspektklassen. München: Wilhelm Fink Verlag.

Landman, Fred. 1991. Structures for Semantics. Dordrecht: Kluwer Academic Publishers.

Mittwoch, Anita. 1991. In Defence of Vendler's Achievements. Perspectives on Aspect and Aktionsart (= Belgian Journal of Linguistics 6), ed. C. Vetters and W. Vandeweghe, 71-85. Bruxelles: Editions de l'Université de Bruxelles.

Moens, Marc, and Mark Steedman. 1988. Temporal Ontology and Temporal Ref erence. Computational Linguistics 14: 15-28.

Mourelatos, Alexander P. D. 1981. Events, Processes, and States. Tense and Aspect (= Syntax and Semantics 14), ed. P. J. Tedeschi and A. Zaenen, 191-212. New York: Academic Press. [1978. Linguistics and Philosophy 2: 415-434.]

Naumann, Ralf. 1995. Aspectual Composition and Dynamic Logic. Düsseldorf: Habilitationsschrift, Heinrich-Heine-Universität.

Parsons, Terence. 1990. Events in the Semantics of English: A Study in Subatomic Semantics. Cambridge, MA: The MIT Press.

Pianesi, Fabio, and Achille C. Varzi. 1994. The Mereo-topology of Event Structures. Proceedings of the Ninth Amsterdam Colloquium, Part III, ed. P. Dekker and M. Stokhof, 527-546. Amsterdam: ILLC/Department of Philosophy, University of Amsterdam.

Piñón, Christopher J. 1995. An Ontology for Event Semantics. Stanford, CA: Ph.D. Dissertation, Stanford University.

Smith, Barry. To appear. Boundaries: An Essay in Mereotopology. The Philosophy of Roderick Chisholm, ed. L. Hahn. LaSalle: Open Court.

Smith, Carlota S. 1991. The Parameter of Aspect. Dordrecht: Kluwer Academic Publishers.

Vendler, Zeno. 1967. Verbs and Times. Linguistics in Philosophy, 97-121. Ithaca: Cornell University Press. [1957. Philosophical Review 12: 39-94.]

Verkuyl, Henk J. 1993. A Theory of Aspectuality: The Interaction between Temporal and Atemporal Structure. Cambridge: Cambridge University Press. 